
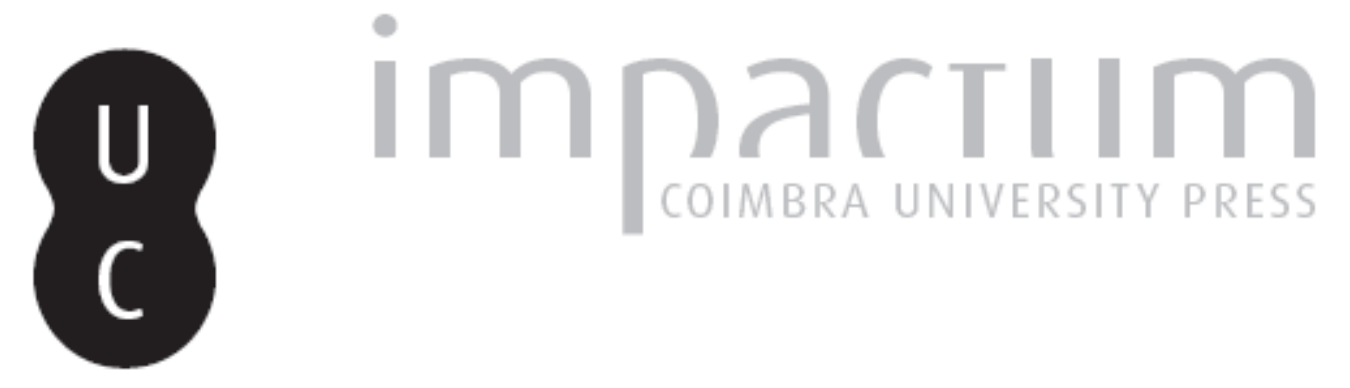

\title{
La doctrina de los tres dioses de Numenio
}

\section{Autor(es): $\quad$ Müller, Gabriela F.}

Publicado por: Annablume Clássica

URL persistente:

URI:http://hdl.handle.net/10316.2/24474

DOI:

DOI:http://dx.doi.org/10.14195/1984-249X_5_2

Accessed : $\quad$ 26-Apr-2023 13:44:42

A navegação consulta e descarregamento dos títulos inseridos nas Bibliotecas Digitais UC Digitalis, UC Pombalina e UC Impactum, pressupõem a aceitação plena e sem reservas dos Termos e Condições de Uso destas Bibliotecas Digitais, disponíveis em https://digitalis.uc.pt/pt-pt/termos.

Conforme exposto nos referidos Termos e Condições de Uso, o descarregamento de títulos de acesso restrito requer uma licença válida de autorização devendo o utilizador aceder ao(s) documento(s) a partir de um endereço de IP da instituição detentora da supramencionada licença.

Ao utilizador é apenas permitido o descarregamento para uso pessoal, pelo que o emprego do(s) título(s) descarregado(s) para outro fim, designadamente comercial, carece de autorização do respetivo autor ou editor da obra.

Na medida em que todas as obras da UC Digitalis se encontram protegidas pelo Código do Direito de Autor e Direitos Conexos e demais legislação aplicável, toda a cópia, parcial ou total, deste documento, nos casos em que é legalmente admitida, deverá conter ou fazer-se acompanhar por este aviso. 

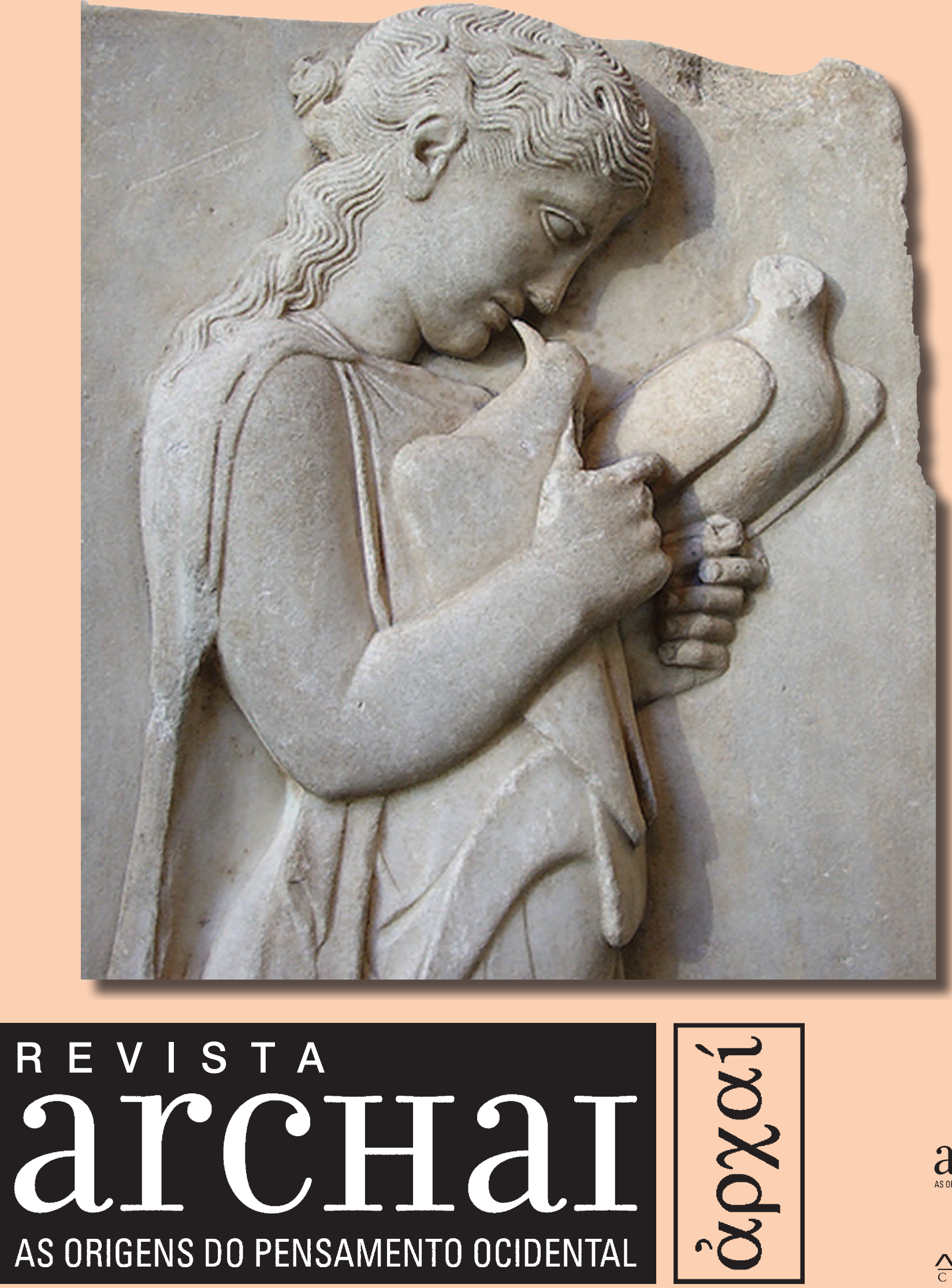


\section{LA DOCTRINA DE LOS TRES DIOSES DE NUMENIO}

RESUMEN: Este trabajo se centrará en la que es quizás la doctrina más característica de Numenio: aquella que, retomando lo dicho en la Carta II atribuida a Platón (312e1-3), sostiene la existencia de tres dioses. Mediante el análisis de algunos fragmentos conservados, intentaré ofrecer una visión de conjunto de la teología numeniana para, de este modo, especificar la particularidad del pensamiento de Numenio en el contexto del platonismo de su época, hecho que hace de él uno de los platónicos de mayor relevancia a la hora de buscar antecedentes del sistema de Plotino.

PALABRAS CLAVE: Numenio, teología, platonismo.

ABSTRACT: This paper will focus on what is perhaps the most characteristic doctrine of Numenius: that which taking into account what is said in the Second Letter attributed to Plato (312 e 1-3), affirms the existence of three gods. By analyzing some preserved fragments, I try to offer an overview of numenian theology to thereby specify the particularity of Numenius' thought in the context of Platonism of his time, fact that makes him one of the most relevant predecessors of Plotinus's system.

KEYWORDS: Numenius, theology, platonism.
1. Universidad de Buenos Aires - CONICET

2. Fr. 24. La numeración de los fragmentos corresponde a la edición de É. des Places

(1973).

3. Cf. fr. $24,1-18$

4. Fr. $24,48-51$.

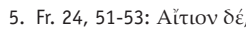

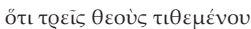

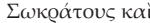

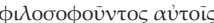

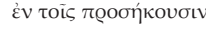

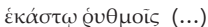

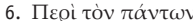

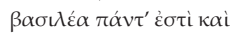

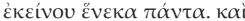

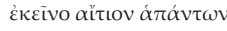
$\tau \tilde{\omega} \nu \kappa \alpha \lambda \tilde{\omega} v \cdot \delta \varepsilon v ́ \tau \varepsilon \circ o v$

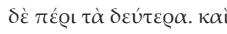

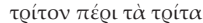

(Carta II $\left.{ }^{a}, 312 \mathrm{e} 1-3\right)$

Sobre la lectura que Numenio hace de este pasaje en conexión con 314 c 2-5 ( $\tau \dot{\alpha} \delta \dot{\varepsilon} v \tilde{v} v \lambda \varepsilon \gamma o ́ \mu \varepsilon v \alpha$

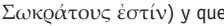
lo llevaría a atribuir esta doctrina a Sócrates, cf.

Ph. Merlan (1962: 138 y 1967: 97).

7. Cf. fr. $24,57-59$
Gabriela F. Müller

I. En un fragmento de una obra de carácter histórico-polémico conservado por Eusebio de Cesárea en el Libro XIV de su Praeparatio evangelica

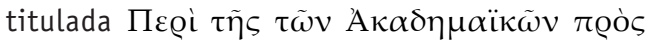

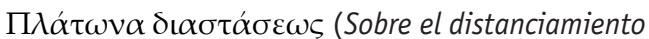
de los Académicos respecto de Platón), ${ }^{2}$ Numenio realiza una crítica a los escolarcas de la Academia (Espeusipo, Jenócrates y Polemón) por no haber mantenido la ómodoçía, la igualdad de opinión, respecto de la doctrina platónica. ${ }^{3}$ Más delante Numenio también denuncia a "los que extrajeron de

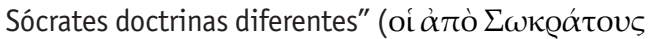

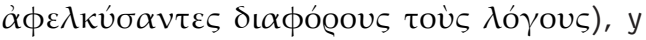
refiere explícitamente a Aristipo, Antístenes, los megáricos y los erétricos. ${ }^{4}$ La causa de esto, según nos dice el propio Numenio, es que desconocían “que Sócrates establecía tres dioses y filosofaba sobre ellos conforme al modo que conviene a cada uno $^{\prime{ }^{5}}$ Claramente este pasaje alude a la doctrina expuesta en la Carta II ${ }^{a}$ (312 e 1-3) atribuida a Platón, que establece tres órdenes diversos de lo real. ${ }^{6}$ Y justamente Numenio continua afirmando que, a diferencia de los otros discípulos, Platón no sólo conocía esta doctrina socrática sino que también sabía que ella provenía de Pitágoras, puesto que él mismo era pitagórico. ${ }^{7}$ 
Lo que encontramos en este fragmento, por lo tanto, es el reconocimiento manifiesto por parte de Numenio de una tradición que postula la existencia de tres dioses, tradición en la cual él se inscribe, pero que se remonta a Pitágoras y cuyos continuadores son nada menos que Sócrates y Platón. De hecho, contamos con dos testimonios de Proclo (frs. 21 y 22) que nos informan sobre este punto. El primero corresponde a la interpretación numeniana del pasaje de Timeo 28c3 y afirma que: “Numenio, habiendo proclamado tres dioses, llama

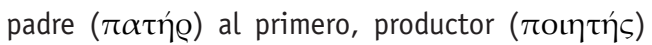
al segundo y producto $\left(\pi \circ \operatorname{lí}_{\mu \alpha} \alpha\right)$ al tercero, pues según él el cosmos es el tercer dios. De modo que,

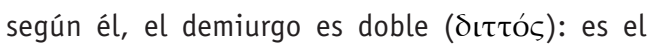
primer dios y el segundo y lo creado (el producto

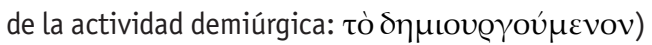
es el tercero $(\ldots)^{\prime \prime}$ El segundo testimonio se encuentra en el contexto del comentario al pasaje de Timeo 39e7-9 y allí dice Proclo: "Numenio ubica al primero en la categoría de "el que es viviente" ('ö $\varepsilon \sigma \tau \iota \zeta \tilde{\omega} O v^{\prime}$ ) y dice que piensa haciendo uso del

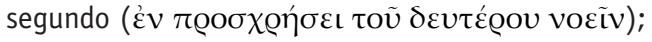
ubica al segundo en la categoría del voũs y dice que éste a su vez crea haciendo uso del tercero

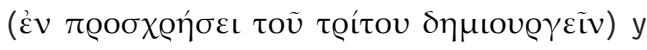
ubica al tercero en la categoría de lo que piensa

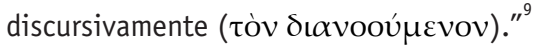

Como puede observarse rápidamente, no es del todo fácil encontrar una absoluta coincidencia entre la descripción de cada uno de estos tres niveles de lo divino en ambos testimonios. Pero el problema es aún mayor dado que en los fragmentos

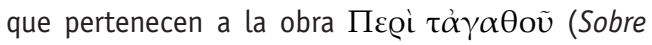
el bien) transmitidos por Eusebio de Cesárea en su Praeparatio evangelica encontramos casi exclusivamente la diferenciación entre un primer dios, identificado con el bien ( $\tau$ ò $\alpha \gamma \alpha \theta$ óv), y un segundo dios, que es un intelecto demiúrgico, y sólo en el fragmento 11 aparece una alusión al tercer dios pero, en principio, sólo para identificarlo con el segundo. ${ }^{10}$ Esto ha llevado a algunos estudiosos a preguntarse si efectivamente Numenio postula tres dioses o sólo dos. ${ }^{11}$ Pero incluso entre quienes aceptan que Numenio adhiere a esta doctrina de los tres dioses, las discrepancias aparecen a la hora de establecer la naturaleza de cada uno de ellos y sus mutuas relaciones.

En este trabajo pretendo no sólo defender la postulación de tres dioses por parte de Numenio sino también intentar aclarar, en la medida en que los fragmentos disponibles lo permiten, los diversos modos en que Numenio caracteriza a cada uno de estos tres dioses para ofrecer una visión de conjunto de la teología numeniana. Me referiré, en primer lugar, a la distinción entre el primer y el segundo dios, para luego pasar al análisis de la duplicidad inherente al segundo dios, lo cual me permitirá, finalmente, ubicar al tercer dios dentro del sistema metafísico de Numenio.

II. En el fragmento 21, Proclo nos transmite la peculiar interpretación que realiza Numenio de la famosa frase de Timeo 28c3, al invertir y atribuir a dos divinidades jerárquicamente diferenciadas los dos apelativos que allí aparecen ( que esta variación respecto del texto del Timeo está atestiguada con anterioridad a Numenio: aparece, por ejemplo, en Plutarco, en la segunda de sus Cuestiones platónicas (1000 E), donde este autor se pregunta acerca de la razón por la cual Platón llamó al dios supremo padre de todas las cosas y

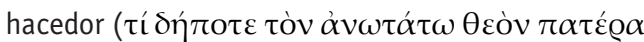

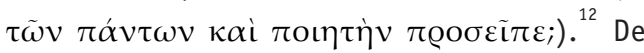
hecho, lejos de ser una práctica extraña o aislada, la inversión en el orden de las palabras respecto del texto platónico es un rasgo estilístico utilizado muy frecuentemente, por ejemplo, en el Didaskalikós de Alcinoo, ${ }^{13}$ pero del que se encuentran rastros en toda la literatura platónica de la época imperial. Esto ha llevado a los intérpretes a concluir que dichas inversiones eran seguramente intencionales y muy probablemente se encontraban ya en las fuentes comunes utilizadas por estos autores. ${ }^{14}$ No obstante, a diferencia de lo que ocurre en un autor como Plutarco, la inversión de estos dos apelativos en Numenio adquiere una nueva dimensión y en ello, creemos, reside su importancia. Como vemos en el testimonio de Proclo, Numenio no sólo invierte el orden de los términos sino que además se sirve de esa inversión para distinguir un primer dios al que
8. Fr. $21=$ Proclus, In Timaeum, I, 303, 27-304, 7 Diehl. Luego de comentar la posición de Numenio y antes de establecer la suya, Proclo hace referencia a las opiniones de Harpocratión, Ático, Plotino, Amelio, Porfirio, Jámblico, Teodoro y Siriano. (Cf. Proclo, In Timaeum, I, 304, 22-310, 2 Diehl).

9. Fr. $22=$ Proclus, In Timaeum, III, 103, 28-32 Diehl.

10. Según la lectura usual de este fragmento, que analizaré en detalle más adelante, allí se sostendría la identidad entre el segundo y el tercer dios. Cf., por ejemplo, J. Dillon (2007: 400).

11. Cf. Ph. Merlan (1967: 100).

12. Plutarco, PQ II, 1000 E. Para un análisis de este pasaje de Plutarco en relación con el texto de Timeo 28c3-5, cf. F. Ferrari (2006: 46-49).

13. Cf. J. Whittaker (1990: XVIII XIX) donde aparece una lista con los ejemplos de estas inversiones en esta obra.

14. Cf. F. Ferrari (2006: 43-58). 


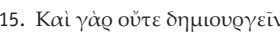

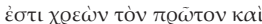

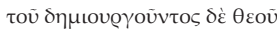

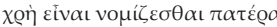

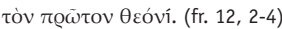

16. Por el contrario, en e testimonio de Calcidio (fr. 52 , 76-78) se afirma que dios es padre del mundo y la materia, madre. En este caso, probablemente pueda verse una referencia no al primero sino al segundo dios que también podría ser llamado "padre" pero del mundo.

17. Para una interpretación distinta de este pasaje, cf. M.

Frede (1987: 1064-1065).

18. Cf. C. M. Herrán (1973: 33 35) quien conecta también este fragmento con el pasaje de Timeo 28 c 3-5 y argumenta, contra

A. J. Festugière (1954: 128 132), que aquí no se trata de la incognoscibilidad del primer dios sino sólo del desconocimiento que los hombres de hecho tienen de él.

19. Cf. Fr. 20

20. M. Bonazzi (2004: 71-84) se ha ocupado de esclarecer la particular interpretación que Numenio realiza de este pasaje de la República (506e6-509b8)

Este autor subraya tres puntos del texto platónico que, según él, condicionan la lectura numeniana. En primer lugar, Sócrates llama a

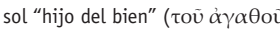
Ě́күovoc) así como Numenio, según el testimonio de Proclo, llama al segundo dios ék $\gamma$ ovoc o

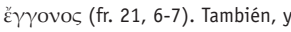
de modo correlativo a la referencia al sol en tanto hijo, Glaucón aclara a Sócrates que les deberá exponer en otra oportunidad "el relato acerca del padre" (

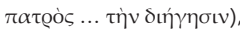
refiriéndose claramente a la explicación sobre el bien que, en virtud de su dificultad,

Sócrates no está en condiciones de dar en ese momento. En segundo lugar, en República el sol es llamado "demiurgo de las

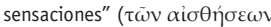

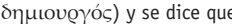
produce ( $\varepsilon \delta \eta \mu t o u ́ \varrho \gamma \eta \sigma \varepsilon v) ~ t$ capacidad de ver y ser visto además que confiere a lo visto la

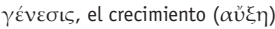

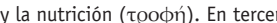
lugar, este autor encuentra en el texto platónico un acercamiento entre la caracterización del soldemiurgo, que es "hijo del bien", y la descripción del voũ y de los objetos inteligibles que obtienen del bien su cognoscibilidad as llama $\pi \alpha \tau \eta ́ \varrho$ y un segundo dios al que denomina

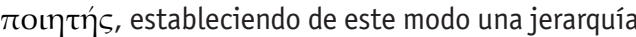
en el interior del ámbito divino.

La misma distinción entre un primer dios que es padre y un segundo dios que es productor o demiurgo aparece en el fragmento 12, donde Numenio afirma: "pues aunque no es necesario que

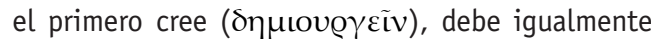
considerarse que el primer dios es padre del dios

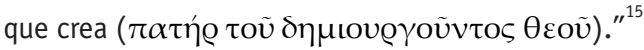
Aquí no sólo se establece la diferencia entre el segundo y el primer dios sino que también se señala el vínculo entre ambos: el primer dios es padre en relación con el segundo dios o demiurgo. ${ }^{16}$ $Y$, si bien la actividad demiúrgica no corresponde propiamente al primer dios, como se aclara de inmediato sí puede decirse que él "produce de

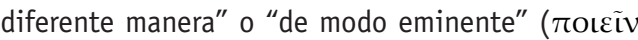

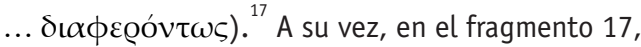
Numenio distingue al demiurgo, que es el único conocido entre los hombres, de un $\pi \varrho \tilde{\omega} \tau o \varsigma$ voũs, que es más antiguo ( $\pi \varrho \tilde{\omega} \tau o \varsigma$ voũ $)$ y más divino

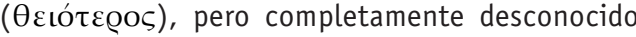

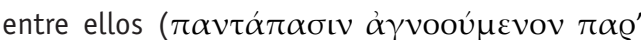

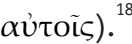

Esta diferenciación puede completarse con un fragmento que corresponde al libro VI del $\varepsilon Q i$ $\tau \dot{\alpha} \gamma \alpha \theta$ oṽ en donde Numenio realiza explícitamente una combinación de pasajes de Timeo y de República para el establecimiento de su sistema metafísico. Dice Numenio: “Platón ha expuesto estas cosas así sostenidas separándolas aquí y allá. Pues, por un lado, en particular en el Timeo escribió sobre el demiurgo en el sentido usual al decir que 'era bueno' ( $\dot{\alpha} \gamma \alpha \theta$ ò $๊ \tilde{v} v)$. Por otro lado, en la República llamó al

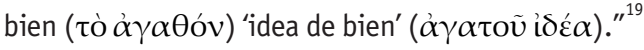
Encontramos aquí distinguidos de manera clara la idea de bien de República y el demiurgo del Timeo. Y al final de este fragmento aparece la relación entre ambas instancias en términos de participación: según Numenio, “si el demiurgo es bueno ( $\dot{\alpha} \gamma \alpha \theta$ ós) por participación en el primer bien ( $\pi \varrho \tilde{\omega} \tau o v$

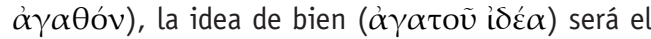
primer voũ $(\pi \varrho \tilde{\omega} \tau o \varsigma$ voũ $)$ ), por ser el bien en sí ( $\alpha$ ủoá $\gamma \alpha \theta o v) . "$ Según Numenio, entonces, este primer dios, que es un primer îiæò, es la idea de bien de la que habló Platón en el contexto de la analogía con el sol de República VI. ${ }^{20}$ Y es la participación en el bien lo que hace que el demiurgo sea bueno, tal como afirma Platón en el Timeo.

Estrechamente vinculada a la noción platónica de participación, en el fragmento 16 Numenio apela al concepto de imitación para explicitar la relación entre el primer dios y el segundo. Numenio comienza ubicando a la oủoí $\alpha$ y a la ióć $\alpha$ en la categoría de lo inteligible (vơtóv) e inmediatamente aclara

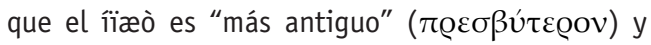
causa ( $\alpha$ ítıov) de la oủoí $\alpha$ y que, por lo tanto, este voũ $\varsigma$ primero es el bien ( $\tau$ ò $\dot{\alpha} \gamma \alpha \theta$ òv). ${ }^{22}$ Por su parte, el dios demiurgo o segundo voũ s es principio

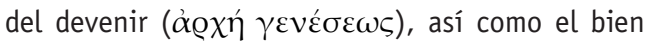
lo es de la oúría. Y la relación que se establece entre ambos (bien y demiurgo) es la de imitación:

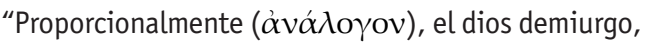
por ser su imitador, es a aquél [al bien] lo que a la

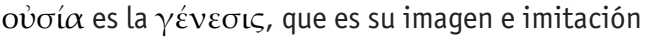

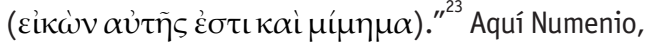
retomando la distinción platónica entre el plano de la oủoí $\alpha$ y el de la $\gamma \varepsilon ́ v \varepsilon \sigma ı s$, establece una relación proporcional entre estos cuatro elementos: el bien o primer voũs es respecto del dios demiurgo 0 segundo voũs lo que la oủoía es a la $\gamma \varepsilon ́ v \varepsilon \sigma ı s$. Pero también se afirma otra correspondencia entre estos planos: hay un demiurgo de la oúoí $\alpha$, que es el bien en sí ( $\alpha u \dot{\tau o \alpha} \gamma \alpha \theta$ ov), y un demiurgo de la $\gamma \varepsilon \dot{v} \varepsilon \sigma \iota \varsigma$. Esto se condice totalmente con el testimonio de Proclo al que hemos hecho referencia antes (fr. 21) donde se decía que el demiurgo era doble: era el primer dios y el segundo.

III. Sin embargo, a continuación en este mismo fragmento 16 Numenio nos dice que el

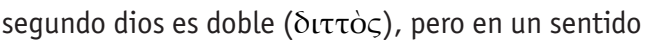
distinto del que encontrábamos en Proclo. Aquí la duplicidad está dada por el hecho de que "el segundo por ser doble, produce por sí mismo, por una parte, la idea de sí mismo y, por otra, el cosmos, por ser demiurgo." ${ }^{24} \mathrm{Y}$ luego Numenio complejiza la distinción trazada anteriormente entre oúoí $\alpha$ y

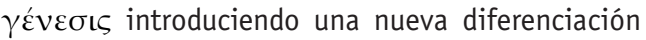

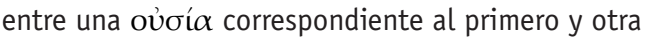
oủoía correspondiente al segundo, de la cual el 
cosmos bello es, a su vez, una imitación. Por lo tanto, nos encontramos aquí con una tripartición: hay una oủoía que es causada por el primer dios o el bien en sí, una segunda oủoía que es la que produce por sí mismo el segundo dios y, por último, el cosmos, que pertenece ya no al plano de la oúoí $\alpha$

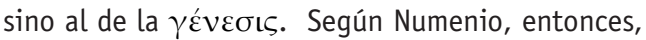
esta segunda instancia de la divinidad posee un aspecto noético que lo vincula a lo inteligible pero también guarda una relación con el ámbito sensible. Esto aparece confirmado en el fragmento 15 donde Numenio distingue la vida del primer dios,

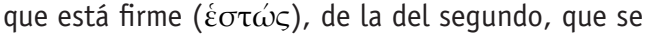

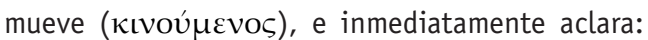
“Por consiguiente el primero [está] en torno a los

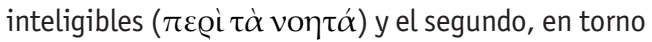

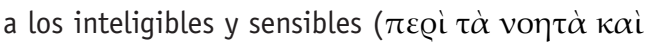
$\alpha i \sigma \theta \eta \tau \alpha ́) . "$ Esta duplicidad presente en el segundo dios, que es a la vez voús y demiurgo, es lo que permite a Numenio el establecimiento de un sistema metafísico que muestra una continuidad sin fisuras entre el plano inteligible y el sensible. Por otra parte, la distinción de un primer voús por encima del voũ s - demiurgo garantiza la total trascendencia del primer principio respecto del ámbito del devenir.

Creo que el segundo de los dos testimonios de Proclo mencionados al comienzo (fr. 22) puede ser entendido en el mismo sentido. Allí Proclo nos habla de tres instancias y de dos actividades: vocĩ

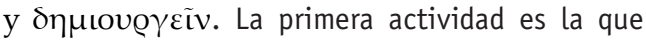

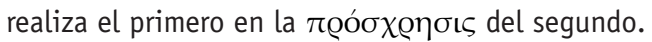
Y esto ayuda a entender por qué, según Numenio,

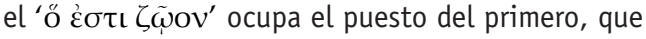
en la mayoría de los fragmentos es identificado con el bien: el primer dios es el modelo que posibilita que el segundo, en tanto voús, pueda ejercer la actividad de la intelección (voeĩv), al igual que el bien es la condición de posibilidad de la intelección de los objetos inteligibles en la analogía con el sol de República VI. Por otra parte, la demiurgia es una actividad que el segundo realiza en la $\pi \varrho o ́ \sigma \chi \varrho \eta \sigma \iota \varsigma$ del tercero. Es decir que el segundo voũ $\varsigma$, a quien propiamente corresponde la actividad noética, es demiurgo en tanto es causa de la $\gamma \varepsilon \dot{v} \varepsilon \sigma \iota \varsigma$ del cosmos sensible y para ello se vale del tercer dios, a quien debe adjudicarse la actividad demiúrgica.
El segundo dios, aquí caracterizado como voũs, entonces, se vincula con ambas actividades según esté relacionado con lo que le antecede o con lo que le sigue dentro de la jerarquía divina. Volveremos más adelante a la caracterización del tercer dios que aparece en este testimonio de Proclo.

Pero antes veamos un fragmento (el fr. 11), el único de entre todos los que nos transmite Eusebio, que también permitiría vincular esta duplicidad del segundo dios con la distinción de un tercer dios. Numenio afirma: “(...) el dios, el primero, estando en sí mismo es simple ( $\alpha \dot{\pi} \lambda$ oũ $\varsigma$, porque al estar enteramente consigo mismo no es jamás divisible

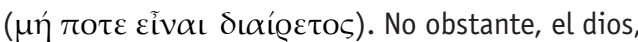
el segundo y tercero, es uno. Pero asociado a la materia, que es díada, por un lado la unifica, pero por otro es escindido por ella" ${ }^{25}$ Aquí Numenio distingue al primer dios que no es divisible, pues es simple, del dios que es segundo y tercero y que, si bien también es una unidad, al estar contrapuesto a una díada, es decir: la materia, y al unificarla, es escindido por ella $\mathrm{y}$, de este modo, deviene, por un lado, segundo, y por otro, tercero. Sobre la base de este fragmento, y teniendo en cuenta los testimonios de Proclo, considero que es posible entender las referencias anteriores al doble aspecto presente en el segundo dios como indicios de la distinción de un tercer dios.

Ahora bien, cabe preguntarse por qué sólo en éste, de entre todos los fragmentos conservados a través de Eusebio, se menciona al tercer dios. Michael Frede ha argumentado que las citas de Numenio provienen de las secciones de la Praeparatio evangelica en las que Eusebio da justificativos para la doctrina platónica de un primer y de un segundo dios. $^{26}$ Sin embargo, en el capítulo 20 del libro XI de la Praeparatio evangelica (capítulo que se titula

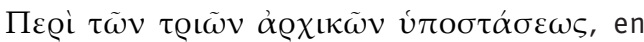
coincidencia con el tratado V 1 de Plotino, que el propio Eusebio ha citado en parte en el capítulo 17 de este mismo libro), Eusebio se ocupa de establecer el acuerdo entre Platón y las Escrituras en lo que respecta a la doctrina de la Trinidad. No obstante, el único texto mencionado allí es el pasaje de la Carta II ${ }^{a}$ (312 e 1-3) de Platón y, a diferencia de lo que ocurría en los capítulo anteriores, donde como su ser y su esencia ( $\tau$ cò

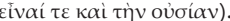
Basándose en estos elementos $\mathrm{M}$. Bonazzi concluye que, a diferencia de la lectura corriente que suele hacerse de esta analogía -el bien es al voús y a las Ideas en el plano inteligible lo que, en el plano sensible, el sol es a las cosas sensibles (cf. H. Dörrie - M. Baltes (1996: 321-324); M. Vegetti (2003: 269))-, Numenio lee en este pasaje una equiparación entre voũs y sol, considerando a ambos como una segunda instancia derivada del bien que se ubica en el ámbito inteligible pero también tiene una incidencia en el plano sensible, en tanto demiurgo de la

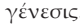

21. Podría interpretarse este pasaje como una suerte de justificación del término "idea" aplicado por Platón al bien. Si las cosas sensibles poseen las características que poseen en virtud de su participación en la idea correspondiente, entonces, el demiurgo para ser bueno tiene que participar en una idea, que es la idea de bien. Cf. también el fr.46 c donde Proclo (In Tim. III, 33, 33-34) nos informa que según Numenio la relación de participación se da también entre los inteligibles.

22. Esta caracterización del primer dios como un voũc que es causa y principio de la oúóí $\alpha$ y, por lo tanto, anterior a ésta, contrasta con la afirmación que hace Numenio unas líneas más adelante cuando dice que el bien en sí ( $\alpha \hat{v} \tau o \alpha ́ \gamma \alpha \theta$ ov) es connatural a

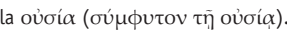
Quizás podría verse aquí una referencia a la necesidad, que existe en toda relación causal, de que haya una cierta comunidad de naturaleza entre la causa y lo causado.

23. Fr. $16,6-8$.

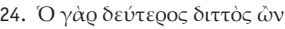

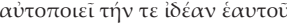

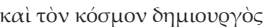
$\omega v$ (fr. 16, 10-12).

25. O Ө

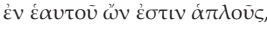

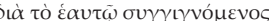

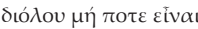

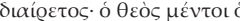

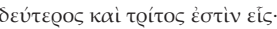

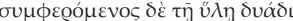

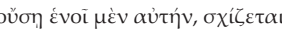

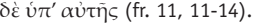

26. Cf. M. Frede (1987: 1056) 
27. Cf. H. D. Saffrey (1975: 49).

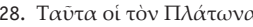

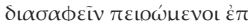

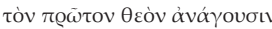

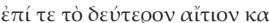

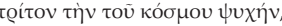

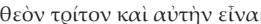

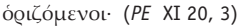

29. Antes de comenzar a citar pasajes del tratado V 1 de Plotino, Eusebio utiliza el mismo verbo

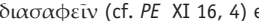
igualmente respecto de Numenio dice que él explica las opiniones

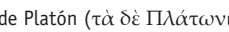

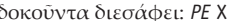

$18,26)$.

30. Considero, con E. R. Dodds (1960: 13-15) que hay que tomar

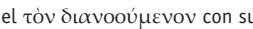
habitual significado medio, en

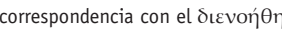
del pasaje del Timeo que Proclo está comentando.

31. C ïP îiææ -ñãiî -! äéqiiiéá- ëëp

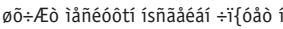
iåñéóôÇ ö\{óåé. (III 9, 1, 35-37).

32. Creo que en este sentido se entiende por qué hay que atribuir la frase $\theta \varepsilon \omega 0 \varepsilon \tau$ เкóc ő $\lambda \omega \varsigma$ Eëùo (fr. 16, 12) al segundo dios. Para una interpretación distinta y la propuesta de una enmienda de texto, cf. E. R. Dodds (1960: 15-16)

33. Cf., entre otros, M. Bonazzi (2004: 79-81) 34. Fr. 52, 5-6 se apelaba constantemente a Numenio y a Plotino con el objeto de explicar determinados pasajes platónicos, aquí no encontramos ninguna referencia a fragmentos de otros platónicos que expliquen el contenido enigmático de este texto. ${ }^{27}$ La pregunta que se impone es: ¿por qué, en este contexto, no se alude a los tres dioses de Numenio o, incluso, a las tres hipóstasis plotinianas? La respuesta, en buena medida, la da el propio Eusebio, a continuación de la cita de este pasaje de la Carta II , al afirmar que "los que intentan explicar ( $\delta\llcorner\alpha \sigma \alpha \phi \varepsilon \tilde{\imath} v)$ a Platón refieren estas cosas al primer dios, a la causa segunda y tercero al alma del cosmos, al delimitar que ella es también tercer dios." ${ }^{28}$ En contraposición a estos platónicos, continúa diciendo Eusebio, las Sagradas Escrituras establecen la Trinidad del Padre, el Hijo y el Espíritu Santo. La razón de la ausencia de citas relativas al tercer dios es evidente: el propósito de Eusebio, como aclara explícitamente en el prólogo a este libro XI, es mostrar el acuerdo que existe entre las doctrinas de los filósofos griegos, principalmente Platón, y las Escrituras. Cuando la interpretación del texto de Platón hecha por algún platónico sirve a este objetivo, Eusebio cita a estos comentadores (esto ocurre, por ejemplo, cuando Eusebio habla de la causa segunda, en los capítulos 14 a 18, y cita sucesivamente a Filón, Platón, Plotino y muy extensamente a Numenio). Pero cuando esto no es así, como en el caso del tercer dios, Eusebio se contenta con la mera referencia al texto platónico cuyo carácter enigmático e indeterminado sirve mejor a su propósito conciliador.

IV. No obstante, en este pasaje, Eusebio nos da una posible pista respecto del tercer dios al decirnos que los que explican este pasaje de Platón lo identifican con el alma del mundo. Estos comentadores de Platón probablemente sean los platónicos mencionados por Eusebio en los capítulos anteriores, esto es: Numenio y Plotino. ${ }^{29}$ Respecto de Plotino, hay abundantes pasajes a lo largo de las Enéadas que ubican al alma en un tercer nivel por debajo de lo uno y del voũ, si bien puede resultar problemática la identificación del alma en tanto hipóstasis con el alma del mundo. Ahora bien, la caracterización del tercer dios de Numenio resulta más complicada. ¿Es posible identificarlo con el alma? Una respuesta definitiva a esta pregunta requeriría un estudio detallado de la psicología numeniana, tema que excede ampliamente los límites de este trabajo. Sin embargo, intentaré ofrecer algunas consideraciones tendientes a avalar esta posibilidad.

En primer lugar, el testimonio de Proclo (fr. 22) nos informa que, según Numenio, el tercer dios

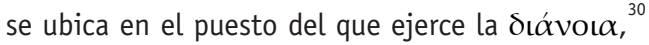
y podríamos suponer que Numenio adhiere a la idea expuesta por Plotino, en pasaje cuyo contenido se encuentra muy cercano a la doctrina numeniana, de

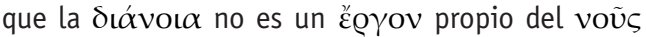
sino del alma. ${ }^{31}$ Por otra parte, en el fragmento 11 Numenio postula al tercer dios como una suerte de escisión ulterior que se produce en el segundo dios en virtud de su acción unificadora sobre la materia. Si esto es así, entonces se comprende bien por qué el segundo dios corresponde propiamente al voũ ejerce la pura actividad noética o contemplativa ${ }^{32}$ y la conformación del cosmos se produce mediante el uso del tercero que es el que planifica dicho orden.

Ahora bien, en el fragmento 21 citado al comienzo Proclo, nos dice que el tercer dios es el $\pi o i ́ \eta \mu \alpha$, lo producido por la actividad demiúrgica

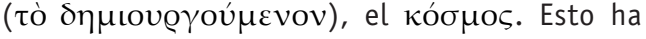
llevado a muchos intérpretes a identificar al tercer dios, no con el alma del mundo, sino directamente con el mundo (entendiendo, por consiguiente, el ôxí äéáiiii $\{$ iăiiií del fr. 22 en sentido pasivo como "lo pensado").

Sin embargo, creo que la principal dificultad para aceptar esta interpretación reside en la caracterización esencialmente dualista del mundo que aparece en el testimonio que nos aporta Calcidio en su Comentario al Timeo (In Timaeum, c. 295-299 = fr. 52 des Places). Allí Calcidio se refiere a la doctrina de Numenio acerca de la relación entre dios y la materia. Siguiendo la doctrina de Pitágoras, que según él coincide con la enseñanza platónica, Numenio llama a dios singularitas y a la materia duitas. ${ }^{34}$ Sin embargo, inmediatamente establece una diferenciación: esta dualidad, en tanto indeterminada, es caracterizada como no generada, sin nacimiento y de la misma edad que el dios por el que es ordenada (aequaevum deo, a quo 
est ordinatum), pero, una vez que es determinada, limitada, adornada y embellecida por dios, que le da forma y orden, es generada (limitatam vero generatam esse). Por lo tanto, esta primera dualidad o díada indeterminada es la materia que ordena el dios demiurgo en vistas a la generación del mundo sensible. $^{35}$ Pero, luego de criticar la concepción estoica que considera a la materia como una naturaleza intermedia, un "género indiferente", Numenio afirma -siguiendo a Pitágoras- que la materia es completamente perjudicial (plane noxia) y que el mundo justamente está compuesto por dios, en tanto causa de los bienes, y la materia, que es causa de los males, o-como han dicho los antiguos teólogos- es producido a partir de providencia y necesidad (fr. 52, 41-42). A pesar de que la acción del dios es persuadir a la materia, adornarla, embellecerla (fr. 52, 9-12), el alma mala que mueve a la materia se opone activamente a la providencia divina y su acción nociva no puede eliminarse del todo (fr. 52, 64-54). Por eso, según nos informa Calcidio, Numenio niega que en el ámbito de la generación pueda encontrarse algo inmune al vicio (fr. 52, 103-104).

La doctrina fuertemente dualista que se desprende de este testimonio impide que se pueda identificar sin más al mundo con un dios, aunque sea tercero. Por otra parte, la alusión en este mismo testimonio a la doctrina platónica que postula dos almas del mundo, una beneficentissima y otra maligna (fr. 52, 64-67), ${ }^{36}$ permite más bien ver al tercer dios como el alma buena del mundo, en tanto garante de su orden. $Y$ en este sentido podría interpretarse que la caracterización del tercer dios como êyóiìò alude justamente a este orden inmanente al universo.

V. Si bien son muchas las dificultades que subsisten en torno a esta doctrina de los tres dioses de Numenio, como hemos visto, algunos puntos importantes pueden ser establecidos con cierta seguridad. Sobre todo podemos ver de qué manera, por un lado, el establecimiento de un primer dios por encima del dios demiurgo que produce el mundo y, por otro, la necesaria distinción dentro del dios segundo de un aspecto puramente noético-contemplativo y un aspecto creador, permiten la conformación de un sistema metafísico jerárquicamente organizado en tres instancias divinas íntimamente relacionadas entre sí, sistema que sin duda dejó su impronta en el platonismo posterior.

En este sentido, y para concluir, quisiera hacer referencia a un pasaje de la Vida de Plotino en el que Porfirio cita el prólogo de una obra de

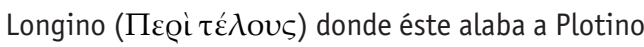
diciendo que expuso los principios pitagóricos y platónicos con más claridad que sus predecesores. ${ }^{37}$ Entre estos predecesores Longino menciona, entre otros, a Numenio y también a Moderato. Por un testimonio del propio Porfirio que conservamos a través del Comentario a la Física de Simplicio, ${ }^{38}$ sabemos que Moderato hablaba de tres unos: ${ }^{39}$ el primero que está sobre el ser y toda oủoía (útì̀

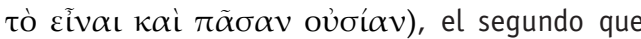
es lo que es verdaderamente y lo inteligible ( $\tau$ ò

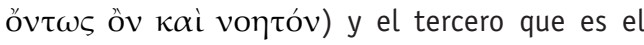
principio psíquico ( $\tau$ ò $\psi v \chi \iota \kappa o ́ v)$. La similitud con las llamadas tres hipóstasis de Plotino es evidente, e incluso se ha sospechado si lo que tenemos en este testimonio no es una proyección porfiriana de la terminología de Plotino. En cualquier caso, si se acepta la reconstrucción aquí propuesta de la doctrina numeniana de los tres dioses, podemos comprender por qué Longino aquí establece una continuidad entre estos tres filósofos. A diferencia de otros platónicos de su época, como Plutarco o Ático, que siguen una dirección más conservadora al postular tres principios (dios, ideas y materia) y que, en general, tienden a negar la existencia de una verdadera jerarquía dentro del ámbito divino, Numenio al igual que Moderato afirma la existencia de tres instancias dentro del plano inteligible. A pesar de la dificultad que entraña la reconstrucción de su pensamiento en base a los escasos y en buena medida problemáticos fragmentos y testimonios que tenemos a nuestra disposición, el estudio de Numenio es sin duda imprescindible para comprender de qué manera la particular interpretación que Plotino realiza de Platón es deudora de los desarrollos realizados por sus predecesores $y$, entre éstos, en particular de Numenio. Si bien la acusación de plagio de la que fue objeto Plotino parece haber sido una exageración y de hecho fue rechazada por
35. Fr. 52, 6-14

36. Cf. Platón, Leyes 896e4-6 y 897 d1.

37. Porfirio, Vida de Plotino, 20 , 70-76

38. Simplicius, In Phys. 230, 34 - 231, 27.

39. Moderato, según este testimonio, afirma que Platón mismo ha sostenido esta doctrina siguiendo a los pitagóricos. En este caso, no sólo debe considerarse la Carta IIa sino también el Parménides de Platón, como ha puesto de manifiesto E. R. Dodds (1928: 136-139) ha puesto de manifiesto. 
40. Cf. Porfirio, Vida de Plotino, 17

41. Cf. Ibid. 3, 43-45
Amelio, ${ }^{40}$ un discípulo de Plotino que era también un reconocido conocedor de Numenio, ${ }^{41}$ creo que es una buena muestra de la gran continuidad que existe entre el pensamiento de ambos filósofos.

\section{Bibliografía}

\section{Fuentes:}

Eusebio:

Mras, K. (1956), Eusebius Werke VIII, Die Praeparatio evangelica, ed. -, Berlin, t. II.

Numenio:

Leemans, E.-A. (1937), Studie over den Wijsgeer Numenius van Apamea met Uitgave der Fragmenten, Bruxelles.

Des Places, É. (1973), Numenius. Fragments, Paris.

García Bazán, F. (1991), Oráculos Caldeos; Numenio de Apamea: Fragmentos y Testimonios, intr., trad. y notas de - , Madrid.

Plotino:

Henry, P. et Schwyzer, H-R (1964-1982), Plotini Opera, ed. -, Oxford, 3 vols.

Igal, J. (1982-1998), Porfirio, Vida de Plotino y Plotino, Enéadas, intr., trad. y notas de -, Madrid, 3 vols.

\section{Bibliografía Secundaria:}

Athanassiadi P. (2006), La lutte pour l'orthodoxie dans le platonisme tardif. De Numénius à Damascius, Paris.

Baltes, M. (1975), “Numenius von Apamea und der platonische Timaios", en Vigiliae Christianae 29, pp. 241-270.

Bonazzi, M. (2004), “Un lettore antico della Repubblica: Numenio di Apamea", en Méthexis, 17, pp. 71-84.

Brisson, L. (1999), "Qualche aspetto della storia del platonismo", en Elenchos, XX, 1, pp. 145-169.

Dillon, J. (1977), The middle Platonists, New York.

- (2007), “Numenius: Some Ontological Questions", en Sharples, R. W. \& Sorabbji, R. (2007), Greek \& Roman Philosophy 100 BC -200 AD, Vol. II, pp. 397- 402.

Dodds, E. R. (1928), “The Parménides of Plato and the Origin of the Neoplatonic One", The Classical Quarterly 22, pp. 129-142.
- (1960), "Numenius and Ammonius", en Les sources de Plotin [Entretiens sur l'antiquité classique, Tomo V], Genève-Vandoeuvres, pp. 1-61.

Dörrie, H.-Baltes, M. (1996), Der Platonismus in der Antike, vol. IV: Die philosophische Lehre des Platonismus, StuttgartBad Cannstatt.

Ferrari, F. (2006), "Poietes kai pater: esegesi medioplatoniche di Timeo, 28c3", en G. De Gregorio - S. Medaglia (eds.), Tradizione, ecdotica, esegesi. Miscellanea di studi, Napoli, pp. 43-58.

Festugière, A. J. (1942-54), La révélation d'Hermès Trismégiste, 4 vols, Paris.

Frede, M. (1987), “Numenios”, en ANRW II, 36.2, 1034-75.

Herrán, C. M. (1973), “El conocimiento místico según Numenio de Apamea", en Cuadernos de Filosofía, XIII/19, pp. 23-37.

Lilla, S. (1992), Introduzione al Medio platonismo, Roma.

Lisi, F. (1977), “Los tres niveles de la divinidad en Numenio de Apamea", en Cuadernos de Filosofía, XVII/26-27, pp.111-130.

Mazzarelli, C. (1982), "Bibliografia medioplatonica. Parte terza: Numenio d'Apamea", Rivista di Filosofia neoscolastica, vol. 74, n. 1, pp. 126-159.

Merlan, Ph. (1962), “Drei Anmerkungen zu Numenios", Philologus, CVI, pp. 137-45.

- (1967), "Greek Philosophy from Plato to Plotinus" en A. H. Armstrong (ed.), The Cambridge History oh Later Greek \& Early Medieval Philosophy, Cambridge, pp 11-132.

Saffrey, H. D. (1975), “Les extraits du Perì tagathoû de Numenius dans le livre XI de la Préparation évangélique d'Eusèbe de Césarée" en Studia Patrística, XIII, Texte und Utersuchungen zur Geschichte der altchristlichen Literatur, CXVI, Berlin, pp. 46-51.

Tarrant, H. (2000), Plato's First Interpreters, New York.

Vegetti, M. (2003), "Megiston Mathema. L'idea del "buono" e le sue funzioni", en M. Vegetti (a cura di), Platone. La Repubblica, vol. V: libri VI-VII, Napoli, pp. 253-286.

Whittaker, J. (1969), “ÅĐÅÊÅÉÉÁ İĩõ ÊÁÉ İÕóÉÉÁó, en Vigiliae christianae, XXIII, pp. 91-104.

- (1987), "Platonic Philosophy in the Early Centuries of the Empire", en ANRW II 36.1, pp. 81-123.

- (1990), Alcinoos. Enseignement des doctrines de Platon, intr., texte établi et commenté par - , et traduit par P. Louis, Paris.

Zambón, M. (2002), Porphyre et le moyen-platonisme, Paris.

Zeller, E. - Mondolfo, R. (1979), La filosofia dei Greci nel suo sviluppo storico, Parte III, vol. IV, Firenze. 